International Journal of Advancement in Life Sciences Research

Online ISSN: $2581-4877$

journal homepage http://ijalsr.org

Review Article

\title{
An Outlook on Migration of Birds and types of Geographical Migratory Patterns
}

\author{
Seema Singh ${ }^{1 *}$, Madhu Sinha ${ }^{1}$, Veena Kumari ${ }^{1}$, Basant Kumar Gupta ${ }^{1}$ and Mohommad Arif ${ }^{2}$ \\ ${ }^{1}$ Deoghar College, Deoghar under Sido Kanhu Murmu University, Jharkhand-814112, India \\ ${ }^{2}$ Defence Institute of Bio-Energy Research (DIBER), HQ, Haldwani, Uttarakhand-263139, India. \\ ${ }^{\star}$ Correspondence E-mail : seemasinghania96@gmail.com
}

\begin{abstract}
Migration is a normal phenomenon in almost all organisms but most communal seasonal phenomenon in birds to find suitable habitats for feeding, breeding and raising their young ones. It allows birds to explore themselves in search of food and to settle in areas where they could otherwise not live. Migratory behaviour has been intensely studied for over a century but there is still mystery in migration of birds that how it originated and how it evolved. Especially the use and evolution of migration routes seems to be a neglected element. Seasonal changes and food supplies are the basic consequence of the evaluation of migratory behaviours. It is still point of discussion, if migratory behaviours have evolved as consequence of not only food but also by competition. Migratory routes probably have come forth out directional preferences which have become fixed by natural selection. Some birds move between their breeding and wintering grounds in a straight line, basically, large crossings are seen from America to Asia. Migratory journeys also occur largely independent of geomorphological and landscape features i.e. broad-front migration. Multiple migratory routes are used by many species in Africa, there is no real preferred migratory route among species. Instead it is believed here that the use of different routes is related to different populations of one species with different breeding grounds, consequently using other routes may cause more distance to travel. The present review work is dealt with different reasons of migration of birds along with types of geographical migratory pattern in birds on the basis of past reviews which already done by the different researchers. Furthermore, much study is needed to reveal many facts regarding bird's migration.
\end{abstract}

Keywords: Migration, Geomorphological, Hypothesis, Southern home and Northern home.

\section{Introduction}

The word 'Migration' has been come from the Latin word 'Migrare' which means going from one spatial unit to another. Any position occupied by an organism at a moment in time is considered as the spatial unit (Prasad, 1948). In bird migration means two-way journey from the breeding (home) place to the feeding place and back journey to the home. Migration is defined as periodic trek (annual journey) of migratory birds, between a specific breeding and non-breeding place in order to take advantage of favourable condition. Migration is the act of changing a resting place, movement from one place to another, 
but technically the word is applied to the passage or movement of birds, fishes, insect and a few mammals between the localities inhabited at different period of the year. The movement of a nomadic tribe of men is migration, the mollusks migrate from feeding ground to feeding ground in the bed of the oceans and the caterpillar migrates from branch to branch, even from leaf to leaf. The rat leaves the ship in which it migrates to a new place. Migrating birds can cover thousands of miles in their annual travels, often traveling periodically the same course annually with little deviation.

Migrating birds can travel very far. They can travel as far as 16,000 miles (Rolland et al, 2014). To reach their destination in time, some travel at speed of $30 \mathrm{mph}$. Some birds migrate at high altitudes like, Songbirds travel at an altitude as high as 500 to 2,000 feet. Geese and vultures have been known to travel at altitudes of 29,000-37,000 feet height (Sekercioglu, 2007). Some scientists believe that birds travel at higher altitudes to conserve energy with less flapping of the wings and more gliding. They move up and down altitudes to gain boosts of natural lift from the changes in density. Long journey for such a small bird was earlier described by Newton, (2008). According to him Hummingbirds are the smallest migrating bird with an average weight of $1 / 8$ of an ounce approximately and can travel as fast as $30 \mathrm{mph}$ (48 kph) when migrating. They fly this nonstop journey which can be as far as 600 miles. Birds prepare themselves for the long journey, for it they build up body fat which is a source of energy for their long journey. They fuel up with certain foods and reserve up to $50 \%$ of their body weight. It is important to feed all year long, but especially when they are preparing to leave for migration and when return from journey.

\section{Historical Visions}

Each of the world's bird species has adapted in some way to this seasonality by making long precisely timed annual movements. Migration is the umbrella term for the immensely capricious movement patterns that birds have evolved for this purpose. One leading theory holds that avian migration evolved by a gradual extension of smaller annual movements as birds searched for improved food or breeding opportunities. Individuals whose movements gave them better chances to survive and reproduce passed that migratory behavior along to their offspring. So, what at one time might have been a short jaunt and might be long over the time due to adverse climates or resources changed.

Birds possess a highly efficient means of travelling over long distances. In the Pacific, Micronesians and Polynesians used traditional landfinding techniques and suggested that bird migration was observed and interpreted for more than 3000 years. In Samoan tradition, Tagaloa sent his daughter Sina to Earth in the form of a bird, Tuli, to find dry land, the word tuli referring specifically to land finding waders, often to the Pacific golden plover (Crowe, 2018).

The Bible also notes migrations, as in the Book of Job, where the inquiry is made: "Is it by your insight that the hawk hovers, spreads its wings southward. The author of Jeremiah wrote: "Even the stork in the heavens know its seasons, and the turtle dove, the swift and the crane keep the time of their arrival. "Aristotle noted that cranes travelled from the steppes of Scythia to marshes at the headwaters of the Nile. Pliny the Elder, in his Historia Naturalis, repeats Aristotle's observations (Lincoln, 1979).

A key force in this evolution may have been the earth's cycles of environmental change over the last 2.5 million years in which more than 20 glacial cycles occurred. The most recent cycle occurred about 15,000 years ago in which melting and retreat of vast ice sheets happened. One can imagine that, with every cycle of Pleistocene glaciation, migrants retreated to more southern breeding localities and made shorter migrations while the ice ruled the north. Then when the ice receded, the migrants moved north to take advantage of renewed breeding opportunities in the unoccupied habitat that emerged.

A recent study of the evolution of migration in the New World warblers makes it clear that migration is not a recent phenomenon of the last few thousand years. Rather, it appears 
likely that the ability to migrate to gamble on the regular appearance of resources someplace else, was a shared trait of all birds, if not all vertebrates.

\section{Hypothesis of Migration}

Along with different reasons of migration the northern home and southern home hypothesis of migration is most discussed topic by different authors and scientists. Finally, two contradictory views emerged about the geographical origin of bird migration. The hypothesis of a northern origin, which assumes that bird migration originated in the current northern temperate zone. The hypothesis of a southern origin, which assumes that migrants stem from the tropics". Two different issues are thereby conflicting to each other, although they are not necessarily associated and are not mutually exclusive. The evolution of seasonal movements in a particular geographical region (bird migration originated in the current northern temperate zone) need not be linked to the phylogenetic origin of the birds (migrants stem from the tropics i.e. phylogenetic origin and evolution of certain traits must not be linked geographically. In addition, the clear dichotomy of the discussion ignores the great diversity of avian migration, including temperate-tropical migration in the southern hemisphere and intra-tropical migration. Therefore, the crucial question for the evolution of bird migration is not whether birds start to migrate from a low latitude origin towards higher latitudes or vice versa. Also whether bird migration evolved from the original breeding areas towards new breeding areas because of enhanced fitness through enhanced reproduction or from breeding areas towards non-breeding areas because of enhanced fitness through better survival in the non-breeding season (Salewski and Bruderer, 2007).

An alternative hypothesis was proposed by Bell (2000), who is the only recent author to propose that bird migration evolved primarily in seasonal breeding areas to spend unfavourable periods on wintering grounds enhancing survival during the non-breeding season. He further elaborated his ideas by discussing that migratory populations arise as a consequence of gradual expansion at the edge of the breeding range (Bell 2005), a theory which came close to the scenarios proposed by Taverner (1904) and Mayr and Meise (1930).

\section{Reason for Bird Migration}

Birds migrate in search of high resources. They move from areas of low or decreasing resources to areas of high or increasing resources. Competition is only one of several factors such as climate, resource availability, predation or parasitism which makes species to shift their breeding ranges and become migrants (Taverner, 1904 and Cox, 1985). Rappole and Tipton (1992) established a consequence to explain how bird migration could have evolved stepwise in resident tropical species through dispersal into favourable breeding areas. These concepts were further elaborated by assuming that migration developed in tropical resident species as a response to pressure on young individuals to locate accepted feeding and breeding habitat. During evolution of the Palearctic-African migration system it was assumed that migrant populations originated from southern regions, shifting their range northwards through long-distance dispersal (Safriel, 1995). All the mentioned studies made competition in the tropical breeding ranges responsible for the evolution of migration out of their ancestral home, whereas Lack (1968) discussed intraspecific competition in the northern breeding areas during the nonbreeding season as being the driving force for at least some individuals (juveniles and females) to migrate out of the breeding areas (Salewski and Bruderer, 2007).

Seasonality of crucial resources was seen as a second important factor for the evolution of migratory behaviour. Some authors interpreted migration as an adaptation to the lack of critical resources in the non-breeding season in temperate regions, optimizing survival during the nonbreeding season (Lucanus 1929; Mayr and Meise 1930; Bell 2000 and Salewski and Bruderer, 2007). Others assumed that migration is an adaptation of tropical birds to use seasonally abundant resources in temperate regions to optimize breeding success (Taverner 1904; Alerstam 
and Enckell 1979; Stiles 1980; Safriel 1995; Rappole 1995; Rappole and Jones 2002 and Salewski and Bruderer, 2007).

Berthold (2001) explained that both strategies are possible. Migration as an adaptation for both, exploiting seasonal peaks of resources and avoiding seasonal resource depression (Alerstam et al, 2003).

Taverner (1904) and Rappole (1995), even though clearly encouraging the "southernhome theory", mentioned deterioration of resources in temperate regions as the reason why birds migrate back to the tropics. Levey and Stiles (1992) developed a scenario for the evolution of Neotropical-Nearctic bird migration where temporal and spatial variation of resources (especially for frugivorous and nectarivorous birds) led to altitudinal intratropical migration, influencing these birds to migrate out of the tropics.

In conclusion, most recent studies have seen bird migration as a result of low latitude populations evolving migration to exploit seasonal resources in temperate regions for breeding. An alternative hypothesis was proposed by Bell (2000), who is the only recent author to propose that bird migration evolved primarily in seasonal breeding areas to spend unfavourable periods on wintering grounds enhancing survival during the nonbreeding season. He further elaborated his ideas by discussing that migratory populations arise as a consequence of gradual expansion at the edge of the breeding range (Bell 2005) and become migrants (Salewski and Bruderer, 2007).

However the two primary resources being sought are food and nesting locations. Birds that nest in the Northern Hemisphere tend to migrate northward in the spring to take advantage of increasing insect populations, budding plants and an abundance of nesting locations (Salewski and Bruderer, 2007). As winter approaches and the availability of insects and other food drops, the birds move south again. Escaping the cold is a motivating factor but many species, including hummingbirds, can withstand freezing temperatures if an adequate supply of food is available (Berthold, 2001).

\section{Nocturnal Migratory Behaviour}

Birds migrates at different time. Many birds migrate during the night. They do this for a variety of reasons. At night, the air is cooler which eliminates the need to stop as much to cool down in water. Similarly, at night there are fewer predators and visibility of these predators is low. Birds are safer traveling when their predators are resting. This is not the case for all birds, as we typically see geese and cranes migrate during the day.

\section{Long-Distance Migration}

Approximately 1800 of the world's 10,000 bird species are long-distance migrants (Sekercioglu, 2007; Rolland et al, 2014 and Salewski and Bruderer, 2007). The tiny artic tern makes the longest migration of any animal in the world. The recent study showed that the average annual round trip lengths about $70,900 \mathrm{~km}(44,100 \mathrm{mi})$ for birds nesting in Iceland and Greenland and about 90,000 (56000 mi) for birds nesting in Netherlands. The typical image of migration is of northern land birds, such as swallows (Hirundinidae) and birds of prey, making long flights to the tropics. However, many Holarctic wildfowl and finch (Fringillidae) species winter in the North Temperate Zone, in regions with milder winters than their summer breeding grounds. For example, the pink-footed goose migrates from Iceland to Britain and neighbouring countries, whilst the dark-eyed junco migrates from subarctic and arctic climates to the contiguous United States and the American goldfinch from taiga to wintering grounds extending from the American South northwestward to Western Oregon. .Some ducks, such as the garganey (Anas querquedula) move completely or partially into the tropics. The European pied flycatcher Ficedula hypoleuca also follows this migratory trend, breeding in Asia and Europe and wintering in Africa.

\section{Geographical Pattern of Migration}

Migration is the regular seasonal movement, often north and south, undertaken by many species of birds. Bird movements basically depends on food availability, habitat and weather. Sometimes journeys are irregular (nomadism, invasions, irruptions) or in only 
one direction (dispersal, movement of young away from natal area) than this type of journeys are not termed as "True migration". Migration is marked by its annual seasonality (Berthold, 2001). Non-migratory birds are said to be resident or sedentary. Many bird populations migrate long distances along a flyway. The most common pattern found is flying north in the spring to breed in the temperate or Arctic summer and returning in the autumn to wintering grounds in warmer regions to the south. Of course, in the southern hemisphere the directions are reversed, but there is less land area in the far south to support long-distance migration (Newton, 2008). In this review article fourteen different migration patterned is discussed below (Prasad, 1948).

I Latitudinal Migration Pattern: It is migration from north to south and vice-versa. Birds migrate from north to south during fall and then in opposite direction during spring. Almost every year many birds travel $3200 \mathrm{~km}$ south to grassland, forest and lakes. Cuckoo breeds in India and spends the summer at south east Africa and thus covers a distance of about $7250 \mathrm{~km}$ (approx.)

II Longitudinal Migration Pattern: Birds migrate from east to west or vice-versa due to unfavourable condition/ periods at their habitat. The starling moves from a breeding area in east Europe or Asia towards the Atlantic coast, to avoid the continental winter. The Patagonian plover visits the Falkland Island and south Pentagonia in September and October in breeding.

III Vertical Migration Pattern: Some animal living in mountainous region move to warmer low lands during winter in search of more foods and suitable shelter. Exswallows and storks migrate a distance of $9650 \mathrm{~km}$ from northern Europe to South Africa.

IV Loop Migration Pattern: Birds that follow the annual circle are loop migrants. Rufous hummingbirds follows this pattern in which they follow two different routes for breeding ground making a circle or loop.
V Diurnal Migration Pattern: Many large birds fly in day. These are crows, swallows, robins, hawks, cranes, pelicans etc. these may be stop to forage in suitable places. These birds usually travel in flock which may be well organized.

VI Nocturnal Migration Pattern: Majority of small sized birds like sparrows, warblers, thrushes etc. prefer to fly at night, under the protection cover of darkness, to escape their enemies. They feed and rest during day.

VII Seasonal Migration Pattern: Some birds migrate at different season of the year for food or breeding. They migrate from the south to north during summer these birds are summer visitors. Ex- cuckoos. There are some birds migrate from north to south during winter they are winter visitors. ExRed wing.

VIII Gametic or Molt Migration Pattern: It occurs in a need to occupy certain environment for successful completion of some parts of the reproductive process. Majority of the duck species perform this type of migration.

IX Drift Migration Pattern: It is rare but highly anticipated event for many birders to see. In this migratory birds are drifted away from their typical migration routes often pushed by storms. Ex- Blue throats and Wrynecks

$X$ Leap frog Migration Pattern: It is a unique pattern where northern population migrates a greater distance to skip over a sedentary population of the same species. A year round range is thus occupied in between the breeding and wintering grounds of the leapfrogging population but the individual population do not extensively mix. It occurs in six subspecies of Fox Sparrow in North America.

XI Irregular Migration Pattern: It is also called erratic or wandering migration. It occurs in heron, cuckoo, thrushes, warblers, gulls, turns etc. They disperse in short or wide areas in search of food and safety from enemies. The adults and the young of such birds may stray from their home after breeding in summer to 
disperse in all directions from their birth place.

XII Partial Migration Pattern: All the member of a group of birds do not take part in migration. Only several members of a group take part. This is called Partial migration. This type of migration occurs in Robins of England, blue birds and many blue jays of Canada and northern United States etc. (Prasad, 1948).

XIII Return Migration Pattern: Migration to a previously known placed which has been visited earlier. Sometimes Great Grey Owl, Woodpecker and coal tit shows such type of migration if they not found sufficient food.

XIV Exploratory Migration Pattern: Migration to a completely unknown space which has not been visited earlier. Although ability to return to the known place is retained, but is not exploited. Ex- Great Grey Owl.

\section{Discussion}

Migration in birds is a very intense and informative topic to study. It is very essential to gather entire possible information about bird's migration for lightning of this topic and making this topic easier for others study. An attempt has made in this study to give a concise information and better understanding regarding reasons of bird migration and different patterns of migration. Present work dealt with an overall historical review, types of geographical patterns.

The study of bird's migration has reached sophisticated levels in many areas, including ecology, behaviour, and physiology. Traditional thoughts of the evolution of migration however have been compromised for several reasons. Previous ideas concerning the ancestral home of migrant species, southern or northern, and whether a partially migratory stage always precedes a fully migratory stage, were not expressed as testable hypotheses. Many researchers plotted migratory behaviour and prepared phylogenetic trees which has become common place and allows tests of traditional hypotheses (Salewski and Bruderer, 2007).
The core idea of most historical views on the evolution of migration is that colonists from a sedentary population find and proliferate in a new environment but are then forced by environmental deterioration to return to their ancestral home (Rappole, 1995; Berthold, 2001). It was not clear whether this has opened over ecological time or over evolutionary time. Several other common themes were expressed, including the necessary assumption that the acquisition of migratory behaviour involved an associated increase in fitness for migrants relative to sedentary individuals, owing to high costs of migration (Strandberg et al., 2010 and Salewski and Bruderer, 2007). Other studies considered whether reliance on a certain food type (e.g. fruit) might predispose populations to be mobile and therefore be pre-adapted to become migratory (Cox, 1985 and Bell, 2005). Some studies (Pulido and Berthold, 2003) frame the discussion of the evolution of migration in the context of proximate and ultimate causes.

The question of geographical directionality was also debated. Two prominent ideas emerged: the 'southern home' and the 'northern home' hypotheses (Rappole, 1995; Salewski \& Bruderer, 2007). These ideas were derived from examining the current distributions of migratory species and their presumed close relatives. The southern home idea assumed that tropical sedentary ancestors experienced episodes of dispersal (either colonists or range expansion), resulting in some individuals reaching northern areas where a super lavishness of summer resources, during interglacial periods at least, gave them enhanced fitness over their sedentary conspecifics, which then presumably went extinct because there was a fitness disadvantage to remaining sedentary (otherwise all species would be continuously distributed with only northern populations migratory). This idea postulates that migrants breeding in north or south temperate regions are returning to their tropical 'ancestral homes' during the winter, and that they should therefore have at least some residual adaptations allowing them to fit into environments very different from those in which they now breed (Pulido et al, 1996). If 
so, this could ameliorate the cost of evolving adaptations to surviving in often radically different breeding and nonbreeding environments (Salewski and Bruderer, 2007).

The northern home has a similar set of ideas but, instead, the ancestral range becomes too difficult for survival and fitness is enhanced by leaving during the winter to a novel home (the tropics), and then returning. This idea is often accompanied by the view that migrants are able to 'fit in' to complex tropical environments by being 'fugitive species' and wandering from one opportunistic wintering area to another, biding their time until environmental conditions on the ancestral northern breeding area once again become hospitable, hence they would return 'home' to breed. Thus, they could avoid the costs of adaptation to tropical habitats by drifting among habitats with some similarity to those in which they breed.

There are two serious issues in phylogenetic mapping. First, experimental and observational studies reveal that the expression of migratory behaviour can change rapidly within a lineage, which can violate assumptions of character mapping. In addition, a species distribution model is used to show that current conditions for obligate migratory populations of the chipping sparrow were much restricted at the Last Glacial Maximum, and that the species might have been considered a partial migrant at that time. Only if the rate of gains and losses of migratory behaviour can be incorporated into a phylogenetic mapping exercise will the actual evolutionary pattern of migration be revealed. For example, reconstruction of the ancestral area and the evolutionary history of migratory categories in a clade of New World warblers depended on the assumptions of character state transitions.

When researchers mention the independent origin of migration in a clade, they are most likely referring to the gain or loss of the expression of the ancestral migratory

\section{References}

Alerstam and Enckell P H. (1979). Unpredictable habitats and evolution of bird migration. Oikos 33, 228-232. programme, not the de novo evolution of migration per se.

It is difficult to think of a superlative concerning avian migration that has not already been expressed multiple times (Berthold, 1996, 1999, 2001). Indeed, skies have been described as being filled with migrating birds, with tales of incredible journeys, physiological feats of endurance, and homing abilities that rival our best Global Positioning System devices.

These behaviours have fascinated us for centuries and our knowledge aspects of migration has become impressive. We know how birds fatten up before migration, how they can fly overwater for hours on end, and that they can use the earth's magnetic field or the stars to navigate. However, placing our knowledge of avian migration in an evolutionary context has been less well accomplished. The present review considers past thoughts on the evolution of migration and suggests an agenda for more future research.

\section{Conclusion}

Four our compounds (Hydroxystigmast-5-en7-one, Oleanonic acid, 5,7,4'-trihydroxy-3,8dimethoxyflavone \& 7,9-dimethoxytariacuripyrone) were isolated from the aerial parts and the leaves of Aristolochia bracteolate. Among them, Hydroxystigmast-5en-7-one \& Oleanonic acid are reported for the first time from the spp. The isolated compounds were identified by measuring its melting point, chromatography methods and NMR spectroscopy.

\section{Acknowledgments:}

The author are thankful to Deoghar College, Deoghar, Department of Zoology, Sido Kanhu Murmu University, India.

\section{Conflicts of Interest:}

The authors declare no conflict of interest.

Alerstam T., Hedenström A., Åkesson S. (2003). Long-distance migration: evolution and determinants. Oikos 103, 247-260. 
Bell, C P. (2000). Process in the evolution of bird migration and pattern in avian Eco geography. $J$ Avian Biol 31, 258-265.

Bell, C P. (2005). The origin and development of bird migration: comments on Rappole and Jones, and an alternative evolutionary model. Ardea 93, 115-123.

Berthold, P. (1995). Microevolution of migratory behaviour illustrated by the Blackcap Sylvia atricapilla: 1993 Witherby Lecture. Bird Study 42, 89-100.

Berthold, P. (2001). Bird Migration: A General Survey. Oxford University Press. 67.

Berthold, P. (1996). Control of bird migration. Chapman and Hall, London.

Berthold, P. (1999). A comprehensive theory for the evolution, control and adaptability of avian migration. Ostrich 70, 1-11.

Cox, G W. (1985) The evolution of avian migration systems between temperate and tropical regions of the New World. Am Nat 126, 451-474.

Crowe, A. (2018). Pathway of the Birds: The Voyaging Achievements of Māori and their Polynesian Ancestors. Auckland, New Zealand: Bateman. ISBN 9781869539610.

Lack D (1968) Bird migration and natural selection. Oikos 19,1-9.

Levey D J and Stiles F G (1992) Evolutionary precursors of long-distance migration: resource availability and movement patterns in Neotropical landbirds. Am Nat 140, 447-476

Lincoln, F. C. (1979). Migration of Birds. Circular 16. Fish and Wildlife Service.

Lucanus F (1929) Die Rätsel des Vogelzuges. Hermann Beyer und Söhne, Langensalza.

Mayr E and Meise W (1930)Theoretis cheszur Geschichtedes Vogelzuges. Vogelzug 1, 149-172

Newton, I. (2008). The Migration Ecology of Birds. Elsevier. Academic Press. pp. 496.
Prasad, A. (1948) Magadh Mahavidyalaya, Refresher (Book) Scientific book company.2, 19-20

Pulido F, Berthold P (2003) Quantitative genetic analysis of migratory behaviour. In: Berthold $P$, Gwinner E, Sonnenschein E (eds) Avian migration. Springer, Berlin Heidelberg New York, pp 53- 77

Pulido F, Berthold P, Van A and Noordwijk J (1996) Frequency of migrants and migratory activity are genetically correlated in a bird population: evolutionary implications. Proc Nat Acad Sci USA 93, 14642-14647.

Rappole J H (1995) The ecology of migrant birdsa neotropical perspective. Smithsonian Institution, Washington.

Rappole $\mathrm{J} \mathrm{H}$ and Jones P (2002) Evolution of old and new world migration systems. Ardea 90:525537

Rappole J H and Tipton A R (1992) The evolution of avian migration in the Neotropics. Ornitol Neotrop 3:45-55 Rappole JH, Helm B, Ramos MA (2003) An integrative framework for understanding the origin and evolution of avian migration. J Avian Biol $34: 124-128$

Safriel, U N. (1995). The evolution of Palearctic migration-the case for southern ancestry. Isr $\mathrm{J}$ Zool 41, 417-431

Salewski, Volker., Bruno, Bruderer. (2007). The evolution of bird migration-a synthesis. Naturwissenschaften. 94, 268-279.

Sekercioglu, C H. (2007). "Conservation ecology: area trumps mobility in fragment bird extinctions". Current Biology. 17 (8), 283-286.

Stiles, F G. (1980). Evolutionary implications of habitat relations between permanent an winter resident landbirds in Costa Rica. In: Keast A, Morton ES (eds) Migrant birds in the neotropics: Ecology, behavior, distribution, and conservation. Smithsonian Institution, Washington, pp 421-435.

Taverner. P A. (1904). A discussion of the origin of migration. Auk 21, 322-333. 